\title{
Skewed Th I Responses Caused by Excessive Expression of Txk, a Member of the Tec Family of Tyrosine Kinases, in Patients with Behcet's Disease
}

\author{
Noboru Suzuki, MD, PhD; Kazuhiko Nara, MD; and Tomoko Suzuki, MD, PhD
}

\begin{abstract}
Behcet's disease (BD) is characterized by recurrent attacks of uveitis, oral aphtha, genital ulcers and skin lesions. The etiology and pathogenesis of BD are largely unknown. It has been reported that excessive ThI cell function is involved in the pathogenesis of BD. Previously, we found that Txk, a member of the Tec family of tyrosine kinases, acts as a ThI cell-specific transcription factor that is involved in the effector function of ThI cells. Thus, we studied ThI cytokine production and Txk expression of T-lymphocytes in patients with BD. Peripheral blood lymphocytes produced excessive ThI-associated cytokines including interferon- $\gamma$ (IFN- $\gamma$ ) and interleukin (IL)- 12 in patients with BD. Circulating CD3+ and purified CD4+ T cells expressed excessive Txk protein. The extent of IFN- $\gamma$ production by the lymphocytes correlated with the expression of Txk protein in the immunoblotting analysis. The majority of cells infiltrating into the skin lesions of patients with BD expressed IFN- $\gamma$. IL- I 2 and IL- 18 were found in the mononuclear cell aggregates in the skin and intestinal lesions of those with BD. Lymphocytes accumulating in the skin and intestinal lesions expressed higher levels of Txk as compared with other Th2-associated diseases. IFN- $\gamma$, IL-I 8 and IL- 12 detected in skin lesions may induce preferential development of ThI cells in patients with BD. Collectively, ThI cells expressing Txk and Th I-associated cytokines may play a critical role in the development of skin and intestinal lesions in patients with BD. This review may serve as a reminder of the importance of excessive ThI cell function in the pathogenesis of $\mathrm{BD}$ and may contribute to the discovery of new molecular targets for the development of a specific therapeutic strategy for BD.
\end{abstract}

Keywords: Behcet's disease, ThI cell,Txk, cytokines

B

ehcet's disease (BD) is characterized by recurrent attacks of oral and genital ulcerations, erythema nodosum, papulopustular skin eruptions, arthritis, uveitis, cerebritis, deep vein thrombosis, and arterial aneurysms. ${ }^{1}$ A T cell-mediated immune response seems to be important in the pathogenesis of BD. ${ }^{2-5} \mathrm{CD} 4+\mathrm{T}$-lymphocytes seem to be the major cell type in inflammatory infiltrates, and increased concentrations of tumor necrosis factor (TNF)- $\alpha$ and interferon- $\gamma$ (IFN- $\gamma$ ) have been described. 6,7

Th1 cells and Th2 cells show distinct patterns of cytokine secretion. Th1 cells typically produce interleukin (IL)-2, IFN- $\gamma$ and TNF- $\beta$, whereas Th2 cells are characterized by their production of IL-4, IL-5, IL-6 and IL-13.8,9 Th1 cells

Reprint Requests: Noboru Suzuki, MD, PhD, Departments of Immunology and Medicine, St. Marianna University School of Medicine, 2-16-I, Sugao, Miyamae-ku, Kawasaki, Kanagawa 2I6-85II, Japan, Tel: 8I-44-977-8III (ext 3545), Fax: 8I-44-975-33I5, E-mail: n3suzuki@marianna-u.ac.jp and Th2 cells cross-regulate the development and function of each subset and establish a Th1/Th2 balance that plays an important regulatory role in the immune system. Many studies have suggested the involvement of the Th1/Th2 balance in autoimmunity. ${ }^{10-12}$ Th1 cytokine promotes acceleration of macrophage function and contributes to organ-specific autoimmunity and delayed-type hypersensitivity. Th2 cytokine attenuates such processes. Polarized Th1/Th2 lymphocytes may play a role in the induction and regulation of immune responses in $\mathrm{BD} .13,14$

We have studied the immune functions of patients with BD. ${ }^{15-23}$ In this review, we summarize the cytokine production profile of patients with $\mathrm{BD}$. In addition, the importance of aberrant expression of Txk, a Tec family tyrosine kinase that acts as a Th1 cell-specific transcription 


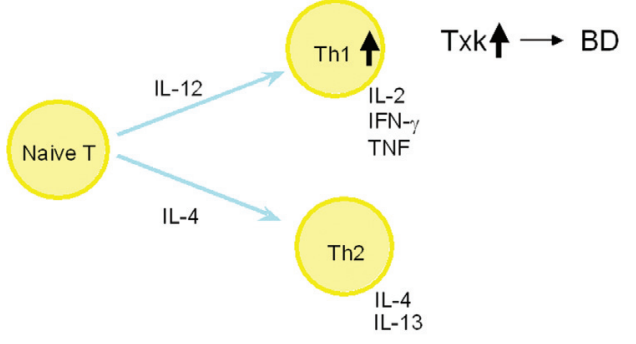

Figure 1. Diagram of Th1 and Th2 cells in Behcet's Disease.

factor, is discussed. After confirming a Th1-dominant phenotype of $\mathrm{BD}$, the production of cytokines with Th1 cell-inducing activity in peripheral blood lymphocytes and skin and intestinal lesions is also discussed.

\section{Excessive Production of Th I Cytokine by Peripheral Blood Lymphocytes in Patients with BD}

Previously, it has been suggested that there is a possible polarization of T-lymphocytes toward the Th1-type in $\mathrm{BD}^{24,25}$ (figure 1). Plasma levels of IL-12, TNF-receptor 75, and soluble IL-2 receptor correlate with disease activity in BD. ${ }^{26}$ Activated macrophages induce cellular immunity by activating Th1 cell responses and by suppressing Th2 cell responses. ${ }^{27}$ IFN- $\gamma$ is a potent immunoregulatory factor that plays an important role in the activation of macrophages by regulating antigen presentation. 8,9 IL-4 can alter the Th1/Th2 balance in the direction of Th 2 cells. Serum IFN- $\gamma$ has been found to be elevated in patients with $\mathrm{BD},{ }^{28}$ and serum IL-12 level has been correlated with disease activity. ${ }^{7,29}$ Analysis of peripheral blood T cells shows increased IFN- $\gamma$ and IL-12 and decreased IL-4 production. ${ }^{29}$ In bronchoalveolar lavage (BAL) fluid from patients with BD, IL-18 is increased. Spontaneously, and after lipopolysaccharide (LPS) stimulation, BAL fluid cells from patients with BD show increased mRNA expression of IFN- $\gamma$ and IL-18 compared with normal controls and patients with silicosis. ${ }^{30}$ These cytokines may act in a synergistic fashion to induce preferential induction of Th1 cells in the BD lesion. In addition, IFN- $\gamma$ mediated autocrine augmentation of Th1 cell induction may have occurred in the BD lesion.

Previously, we have reported that peripheral blood lymphocytes without in vitro stimulation produced IFN- $\gamma$ and IL-12 excessively in patients with BD. Spontaneous IL-4 production in these patients was almost comparable to that of normal controls. ${ }^{20}$

Heat shock protein (HSP) has been assigned a pivotal role in the pathogenesis of BD. ${ }^{31-33}$ Studies have shown that T cells from patients with $\mathrm{BD}$ respond to selected peptides derived from human HSP. 15,34,35 Thus, we studied the cytokine production by peripheral blood lymphocytes stimulated with the HSP-derived peptide 336-351. It was found that IFN- $\gamma$, TNF- $\alpha$, and IL-12 were excessively produced, whereas productions of IL-4, IL-10, and transforming growth factor- $\beta$ were almost normal. ${ }^{20}$ Furthermore, we did not find any significant association between disease activity and Th1-associated cytokine production in patients with BD. These results suggested that HSP-reactive $T$ cells predominantly produce IFN- $\gamma$, and a majority of them can be categorized as Th1 cells in patients with BD. However, others have reported that the cytokine production profile has a mixed Th1/Th2 cell type in active BD. ${ }^{36}$

Results of our study also revealed that normal levels of Th2-type cytokine production were recognized in the patients with BD. Thus, excessive activity of Th1 cells, not a relative increase in the Th1 cell versus Th2 cell activity, may be important for the pathogenesis of BD.

\section{Th I Cytokine Production in the Skin and Intestinal Lesions of Patients with BD}

IL-12, IFN- $\gamma$ and MCP-1 expressions are increased in mucocutaneous lesions, such as oral ulcers, genital ulcers, pseudofolliculitis and lesions from the site of a positive pathergy test result. $37,38 \mathrm{We}$ studied IL-4 and IFN- $\gamma$ producing cells in the mononuclear cell aggregates of the skin lesions of patients with BD. In the erythema nodosum in patients with $\mathrm{BD}, \mathrm{IFN}-\gamma$ producing cells were detected in the mononuclear cell infiltrating area, and IL-4 producing cells were scarcely detected. Ulcerated lesions of the scrotal skin of patients with BD revealed IFN- $\gamma$ mRNA expression. Thus, Th1 cells may predominantly infiltrate in the skin lesions of patients with BD.

In ileocaecal lesions of patients with $\mathrm{BD}$, mononuclear cell infiltration has been observed, and the majority of the infiltrating cells have been CD4+ cells. IFN- $\gamma$, TNF- $\alpha$, and IL-12 along with IL-12R $\beta 2$ mRNA have been detected in the ileocaecal ulcers of BD patients. ${ }^{19}$ A skewed Th1/Th2 cytokine balance toward Th1 is often evident in the skin and intestinal lesions of patients with BD.

\section{Txk Expression of Peripheral Blood T cells, Skin and Intestinal Lesions in Patients with BD}

Txk/Rlk is a member of the Tec family of non-receptor tyrosine kinases, including Tec, Btk, Itk/Tsk/Emt, and Bmx (figure 2). All Tec family kinases are significantly involved in the lymphocyte signaling pathways. ${ }^{39-47}$ Txk is a signal-transducing molecule, which consists of the tyrosine kinase cascade downstream from the $\mathrm{T}$ cell receptor when an antigen is presented to the $\mathrm{T}$ cell through the $\mathrm{T}$ cell receptor. Txk is phosphorylated and activated by Fyn, one of the Srk family kinases, and it phosphorylates downstream signal molecules.

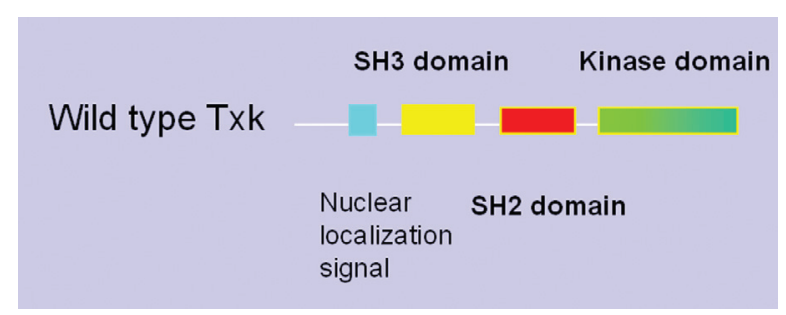

Figure 2. Structure of Txk, a member of the Tec family non-receptor tyrosine kinases. 


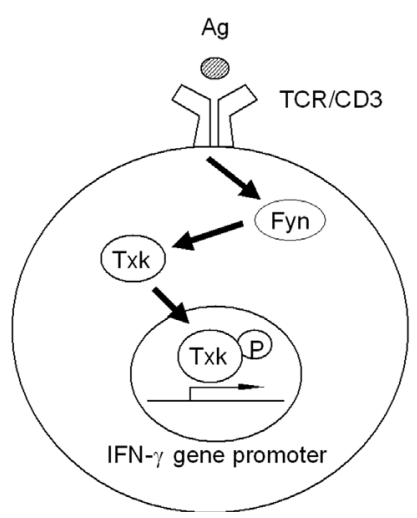

Figure 3. Schematic representation of molecular mechanisms of action of Txk as a Th1 cell-specific transcription factor.

We have reported that Txk expression is restricted to Th1/Th0 cells with IFN- $\gamma$ producing potential. Txk transfection has resulted in a several-fold increase in IFN- $\gamma$ mRNA expression and protein production by upregulating IFN- $\gamma$ enhancer activity. Thus, Txk acts as a Th1 cell-specific transcription factor $^{46,47}$ (figure 3). We studied whether aberrant expression of Txk is involved in the immunopathogenesis of BD. Peripheral blood lymphocytes from patients with BD expressed Txk much more than did the peripheral blood lymphocytes from normal controls. When purified CD3+ and CD4+ $\mathrm{T}$ cell subpopulations were studied, both $\mathrm{CD} 3+\mathrm{T}$ cells and $\mathrm{CD} 4+\mathrm{T}$ cells expressed excessive amounts of Txk protein in the majority of patients with $\mathrm{BD}$ as compared to normal controls.

We studied the association of Txk protein expression and cytokine production of lymphocytes. To this end, CD3+ cells were simultaneously tested for IFN- $\gamma$ production by the enzyme-linked immunosorbent assay and for Txk protein expression by immunoblotting. We found that the extent of IFN- $\gamma$ production by the lymphocytes correlated with the expression of Txk protein in the blot. Thus, it is likely that the excessive expression of Txk leads to Th1-dominant immune responses and subsequently to the skewed $\mathrm{Th} 1 / \mathrm{Th} 2$ balance in the pathogenesis of $\mathrm{BD}$.

Txk protein was expressed in the mononuclear cell aggregates of erythema nodosum in patients with BD. Ulcerated lesions of the scrotal skin of a patient with $\mathrm{BD}$ revealed Txk mRNA expression. In intestinal lesions of BD, in which Th1-related cytokine was expressed excessively, mRNA of Txk was detected. These findings suggest that Txk may contribute to Th1 skewed cytokine balance through enhancement of IFN- $\gamma$ gene expression in the $\mathrm{BD}$ lesions.

The involvement of other transcription factors in the progression of BD has been suggested. T-bet and GATA-3 are major switches for Th1 and Th2 development, respectively. The involvement of T-bet has been suggested in BD. 48 A small amount of T-bet is expressed in the naive CD4 T cells of normal individuals. Recognition of an antigen in the presence of IFN- $\gamma$ induces T-bet expression followed by the induction of IL-12R $\beta 2$ expression by T-bet, which results in increased IFN- $\gamma$ expression through the augmented signals from IL-12R and IL-18R. Peripheral blood mononuclear cells from patients with BD and active uveitis have shown prominently increased T-bet expression. ${ }^{48}$

Chemokine Receptor Expression in Patients with BD Polarized Th1 and Th2 subtypes express distinct chemokine receptor profiles. Differential expression of chemokines and their receptors within inflamed tissues and lymphoid organs may direct tissue-specific trafficking of Th1/Th2 cells to areas in which their accumulation has been observed. CXCR3 and, to a lesser extent, CCR5 are expressed at higher levels on Th1 cells. ${ }^{49,50}$ CCR3, CCR 4 and CCR 8 are preferentially expressed on Th2 cells. We analyzed the expression of chemokine receptors on peripheral blood lymphocytes. ${ }^{19}$ CCR5 was expressed in all the samples of peripheral blood lymphocytes, whereas CXCR3 was detected in $75 \%$ of patients with BD. In contrast, CCR3, a Th2-specific chemokine receptor, was detected only in patients with BD who were in the inactive phase of the disease. CCR4, another Th2-specific chemokine receptor, was detected in two of eight patients with $\mathrm{BD}$. All the chemokine receptors examined were detected from the peripheral blood lymphocytes of normal controls. Subsequently, we investigated the mRNA of chemokine receptors expressed in the intestinal lesions of patients with BD. CXCR3 and CCR5 mRNA expression was detected in all intestinal tissue samples from patients with BD. On the contrary, CCR4 mRNA was detected in an intestinal lesion of a patient with ulcerative colitis who lacked mRNA of the Th1-related chemokine receptor including CXCR3 and CCR5. MIP1 $\alpha$, MIP1 $\beta$ and RANTES are able to bind to CCR5, and MIP1 $\beta$ mRNA was detected in all intestinal lesions of the patients with $\mathrm{BD}$. The chemokine receptor expression patterns coincided with the Th1-dominant immune response in patients with $\mathrm{BD}$.

\section{Production of Cytokines that Induce ThI Cell Differentiation in the Skin and Intestinal Lesions}

We examined the production of TNF- $\alpha$, IL-12, IL-18 and IFN- $\gamma$ which may affect Th1 cell development in the skin and intestinal lesions of patients with BD. IL-12, IL-18 and IFN- $\gamma$ have been shown to positively modulate Th1 cell induction. 8,9 Furthermore, pretreating normal T cells with IL-12, IL-18 and IFN- $\gamma$ from normal $\mathrm{T}$ cells resulted in upregulated Txk protein expression (Suzuki et al., manuscript in preparation). Thus, if the Th1-associated cytokines are produced in situ, differentiation of naive $T$ cells into Th1 cells may be enhanced in the skin and intestinal lesions of patients with BD. Indeed, we found IL-12, IL-18 and IFN- $\gamma$ producing cells in the mononuclear cell infiltrating area of the skin lesions of patients with BD. Thus, Th1-associated cytokines may lead to preferential development of Th1-dominant responses in situ in patients with BD. These data suggest that local production of the Th1-associated cytokines and accumulation of Txk expressing lymphocytes may be involved in the pathogenesis of BD. 
Our results suggest that the expression of Txk by Th1 cells may be involved in the pathogenesis of skin and intestinal lesions in patients with BD. The presence of Th1 cells in the skin lesions of patients with BD may result in the induction of an inflammatory process. Txk activity, as an enhancer of IFN- $\gamma$ gene transcription, is dependent on phosphorylation of certain tyrosine residues of Txk. Thus, the phosphorylated tyrosine residues of Txk may be one of the potential targets of pharmacological therapy.

In conclusion, the accumulation of Th1 cells expressing Txk protein may play a role in the pathogenesis of $\mathrm{BD}$, and Th1-type cytokines may contribute to the immunopathogenesis of BD. In accordance with our findings, the importance of excessive HSP60 expression and HSP-reactive Th1 cells has been reported. ${ }^{10,13,32,33}$ Both, have been intimately associated with the development of inflammation and autoimmunity in this disease. We hope that our findings for the pathogenesis of BD may contribute to the development of a new therapeutic strategy for this disease in the near future.

\section{References}

1. Sakane T, Takeno M, Suzuki N, Inaba G. Behcet's disease. N Engl J Med 1999;341:1284-1291.

2. Gul A. Behcet's disease: an update on the pathogenesis. Clin Exp Rheumatol 2001;19:S6-S12.

3. Yurdakul S, Hamuryudan V, Yazici H. Behcet syndrome. Curr Opin Rheumatol 2004;16:38-42.

4. Zouboulis CC, May T. Pathogenesis of Adamantiades-Behcet's disease. Med Microbiol Immunol (Berl) 2003;192:149-155.

5. Direskeneli H. Behcet's disease: infectious aetiology, new autoantigens, and HLA-B51. Ann Rheum Dis 2001;60:996-1002.

6. Mege JL, Dilsen N, Sanguedolce V, Gul A, Bongrand P, Roux H, Ocal L, Inanc M, Capo C. Overproduction of monocyte derived tumor necrosis factor alpha, interleukin (IL) 6, IL-8 and increased neutrophil superoxide generation in Behcet's disease. A comparative study with familial Mediterranean fever and healthy subjects. J Rheumatol 1993;20:1544-1549.

7. Frassanito MA, Dammacco R, Cafforio P, Dammacco F. Th1 polarization of the immune response in Behcet's disease: a putative pathogenetic role of interleukin-12. Arthritis Rheum 1999:42:1967-1974.

8. Szabo SJ, Sullivan BM, Peng SL, Glimcher LH. Molecular mechanisms regulating Th1 immune responses. Annu Rev Immunol 2003;21:713-758.

9. Murphy KM, Ouyang W, Farrar JD, Yang J, Ranganath S, Asnagli H, Afkarian M, Murphy TL. Signaling and transcription in T helper development. Annu Rev Immunol 2000;18:451-494.

10. Houman H, Hamzaoui A, Ben Ghorbal I, Khanfir M, Feki M, Hamzaoui K. Abnormal expression of chemokine receptors in Behcet's disease: relationship to intracellular Th1/Th2 cytokines and to clinical manifestations. J Autoimmun 2004;23:267-273.

11. Saruhan-Direskeneli G, Yentur SP, Akman-Demir G, Isik N, Serdaroglu P. Cytokines and chemokines in neuro-Behcet's disease compared to multiple sclerosis and other neurological diseases. J Neuroimmunol 2003;145:127-134.

12. Raziuddin S, al-Dalaan A, Bahabri S, Siraj AK, al-Sedairy S. Divergent cytokine production profile in Behcet's disease. Altered Th1/Th2 cell cytokine pattern. J Rheumatol 1998;25:329-333.
13. Houman H, Hamzaoui A, Ben Ghorbal I, Khanfir MS, Feki M, Hamzaoui $\mathrm{K}$. Tc1/Tc2 ratio in the inflammatory process in patients with Behcet's disease. Mediators Inflamm 2004;13:247-253.

14. Hegab S, Al-Mutawa S. Immunopathogenesis of Behcet's disease. Clin Immunol 2000;96:174-186.

15. Kaneko S, Suzuki N, Yamashita N, Nagafuchi H, Nakajima T, Wakisaka S, Yamamoto S, Sakane T. Characterization of T cells specific for an epitope of human $60-\mathrm{kD}$ heat shock protein (hsp) in patients with Behcet's disease (BD) in Japan. Clin Exp Immunol 1997;108:204-212.

16. Wakisaka S, Takeba Y, Mihara S, Takeno M, Yamamoto S, Sakane T, Suzuki N. Aberrant Fas ligand expression in lymphocytes in patients with Behcet's disease. Int Arch Allergy Immunol 2002;129:175-180.

17. Suzuki N, Kaneko S, Ichino M, Mihara S, Wakisaka S, Sakane $\mathrm{T}$. In vivo mechanisms for the inhibition of T lymphocyte activation by long-term therapy with tacrolimus (FK-506): experience in patients with Behcet's disease. Arthritis Rheum 1997:40:1157-1167.

18. Kurokawa MS, Yoshikawa H, Suzuki N. Behcet's disease. Semin Respir Crit Care Med 2004;25:557-568.

19. Imamura Y, Kurokawa MS, Yoshikawa H, Nara K, Takada E, Masuda C, Tsukikawa S, Ozaki S, Matsuda T, Suzuki N. Involvement of Th1 cells and heat shock protein 60 in the pathogenesis of intestinal Behcet's disease. Clin Exp Immunol 2005;139:371-378.

20. Nagafuchi H, Takeno M, Yoshikawa H, Kurokawa MS, Nara K, Takada E, Masuda C, Mizoguchi M, Suzuki N. Excessive expression of Txk, a member of the Tec family of tyrosine kinases, contributes to excessive Th1 cytokine production by T lymphocytes in patients with Behcet's disease. Clin Exp Immunol 2005;139:363-370.

21. Suzuki Kurokawa M, Suzuki N. Behcet's disease. Clin Exp Med 2004;4:10-20.

22. Takeno M, Shimoyama Y, Kashiwakura J, Nagafuchi H, Sakane T, Suzuki N. Abnormal killer inhibitory receptor expression on natural killer cells in patients with Behcet's disease. Rheumatol Int 2004;24:212-216.

23. Wakisaka S, Takeba Y, Mihara S, Takeno M, Yamamoto S, Sakane T, Suzuki N. Aberrant Fas ligand expression in lymphocytes in patients with Behcet's disease. Int Arch Allergy Immunol 2002;129:175-180.

24. Rajendram R, Rao NA. Molecular mechanisms in Behcet's disease. Br J Ophthalmol 2003;87:1199-1200.

25. Sugi-Ikai N, Nakazawa M, Nakamura S, Ohno S, Minami M. Increased frequencies of interleukin-2- and interferon-gamma-producing $\mathrm{T}$ cells in patients with active Behcet's disease. Invest Ophthalmol Vis Sci 1998;39:996-1004.

26. Turan B, Gallati H, Erdi H, Gurler A, Michel BA, Villiger PM. Systemic levels of the T cell regulatory cytokines IL-10 and IL-12 in Bechcet's disease; soluble TNFR-75 as a biological marker of disease activity. J Rheumatol 1997;24:128-132.

27. Desmedt M, Rottiers P, Dooms H, Fiers W, Grooten J. Macrophages induce cellular immunity by activating Th1 cell responses and suppressing Th2 cell responses. J Immunol 1998; 160:5300-5308

28. Hamzaoui K, Ayed K, Slim A, Hamza M, Touraine J. Natural killer cell activity, interferon-gamma and antibodies to herpes viruses in patients with Behcet's disease. Clin Exp Immunol 1990;79:28-34.

29. Hamzaoui K, Hamzaoui A, Guemira F, Bessioud M, Hamza M, Ayed K. Cytokine profile in Behcet's disease patients. Relationship with disease activity. Scand J Rheumatol 2002;31:205-210 
30. Hamzaoui A, Ghrairi H, Ammar J, Zekri S, Guemira F, Hamzaoui K. IL-18 mRNA expression and IFN-gamma induction in bronchoalveolar lavage from Behcet's disease. Clin Exp Rheumatol 2003;21:S8-S14.

31. Eglin RP, Lehner T, Subak-Sharpe JH. Detection of RNA complementary to herpes-simplex virus in mononuclear cells from patients with Behcet's syndrome and recurrent oral ulcers. Lancet 1982;2:1356-1361.

32. Lehner T. The role of heat shock protein, microbial and autoimmune agents in the aetiology of Behcet's disease. Int Rev Immunol 1997;14:21-32.

33. Direskeneli H, Saruhan-Direskeneli G. The role of heat shock proteins in Behcet's disease. Clin Exp Rheumatol 2003;21:S44-S48.

34. Pervin K, Childerstone A, Shinnick T, Mizushima Y, van der Zee R, Hasan A, Vaughan R, Lehner T. T cell epitope expression of mycobacterial and homologous human 65-kilodalton heat shock protein peptides in short term cell lines from patients with Behcet's disease. J Immunol 1993;151:2273-2282.

35. Direskeneli H, Eksioglu-Demiralp E, Yavuz S, Ergun T, Shinnick T, Lehner T, Akoglu T. T cell responses to 60/65 $\mathrm{kDa}$ heat shock protein derived peptides in Turkish patients with Behcet's disease. J Rheumatol 2000;27:708-713.

36. Raziuddin S, al-Dalaan A, Bahabri S, Siraj AK, al-Sedairy S. Divergent cytokine production profile in Behcet's disease. Altered Th1/Th2 cell cytokine pattern. J Rheumatol 1998;25:329-333.

37. Mumcu G, Ergun T, Elbir Y, Eksioglu-Demiralp E, Yavuz S, Atalay T, Direskeneli H. Clinical and immunological effects of azithromycin in Behcet's disease. J Oral Pathol Med 2005;34:13-16.

38. Gul A, Esin S, Dilsen N, Konice M, Wigzell H, Biberfeld P. Immunohistology of skin pathergy reaction in Behcet's disease. Br J Dermatol 1995;132:901-907.

39. Schwartzberg PL, Finkelstein LD, Readinger JA. TEC-family kinases: regulators of T-helper-cell differentiation. Nat Rev Immunol 2005;5:284-295.

40. Berg LJ, Finkelstein LD, Lucas JA, Schwartzberg PL. Tec family kinases in T lymphocyte development and function. Annu Rev Immunol 2005;23:549-600.

41. Lindvall JM, Blomberg KE, Valiaho J, Vargas L, Heinonen JE, Berglof A, Mohamed AJ, Nore BF, Vihinen M, Smith CI. Bruton's tyrosine kinase: cell biology, sequence conservation, mutation spectrum, siRNA modifications, and expression profiling. Immunol Rev 2005;203:200-215.

42. Guo S, Ferl GZ, Deora R, Riedinger M, Yin S, Kerwin JL, Loo JA, Witte ON. A phosphorylation site in Bruton's tyrosine kinase selectively regulates $\mathrm{B}$ cell calcium signaling efficiency by altering phospholipase C-gamma activation. Proc Natl Acad Sci U S A 2004;101:14180-14185.

43. Miller AT, Wilcox HM, Lai Z, Berg LJ. Signaling through Itk promotes $\mathrm{T}$ helper 2 differentiation via negative regulation of T-bet. Immunity 2004;21:67-80.

44. Takeno M, Yoshikawa H, Kurokawa M, Takeba Y, Kashiwakura JI, Sakaguchi M, Yasueda H, Suzuki N. Th1-dominant shift of T cell cytokine production, and subsequent reduction of serum immunoglobulin E response by administration in vivo of plasmid expressing Txk/Rlk, a member of Tec family tyrosine kinases, in a mouse model. Clin Exp Allergy 2004;34:965-970.

45. Kashiwakura J, Suzuki N, Takeno M, Itoh S, Oku T, Sakane T, Nakajin S, Toyoshima S. Evidence of autophosphorylation in Txk: Y91 is an autophosphorylation site. Biol Pharm Bull 2002;25:718-721.

46. Takeba Y, Nagafuchi H, Takeno M, Kashiwakura J, Suzuki N. Txk, a member of nonreceptor tyrosine kinase of Tec family, acts as a Th1 cell-specific transcription factor and regulates IFN-gamma gene transcription. J Immunol 2002;168:2365-2370.
47. Kashiwakura J, Suzuki N, Nagafuchi H, Takeno M, Takeba Y, Shimoyama Y, Sakane T. Txk, a nonreceptor tyrosine kinase of the Tec family, is expressed in T helper type 1 cells and regulates interferon gamma production in human $\mathrm{T}$ lymphocytes. J Exp Med 1999;190:1147-1154.

48. Li B, Yang P, Zhou H, Zhang Z, Xie C, Lin X, Huang X, Kijlstra A. T-bet expression is upregulated in active Behcet's disease. Br J Ophthalmol 2003;87:1264-1267.

49. Mackay CR. Follicular homing T helper (Th) cells and the Th1/Th2 paradigm. J Exp Med 2000;192:F31-F34.

50. Campbell JD, HayGlass KT. T cell chemokine receptor expression in human Th1- and Th2-associated diseases. Arch Immunol Ther Exp (Warsz) 2000;48:451-456.

\section{Author Affiliations}

Noboru Suzuki, MD, PhD; Departments of Immunology and Medicine, St. Marianna University, School of Medicine, Kawasaki, Kanagawa 216-8511, Japan

Kazuhiko Nara, MD; Departments of Immunology and Medicine, St. Marianna University School of Medicine, Kawasaki, Kanagawa 216-8511, Japan

Tomoko Suzuki, MD, PhD; Departments of Immunology and Medicine, St. Marianna University School of Medicine, Kawasaki, Kanagawa 216-8511, Japan 